\title{
(In) segurança dos monitores multiparamétricos na cirurgia cardíaca: um estudo de acurácia diagnóstica
}

\section{(In)security of multiparameter monitors in cardiac surgery: a diagnostic accuracy study}

\section{(In) seguridad de los monitores multiparamétricos en la cirugía cardíaca: un estudio de precisión diagnóstica}

Recebido: 04/08/2019

Aprovado: 29/12/2019

Publicado: 17/02/2020

\section{Andrezza Serpa Franco ${ }^{1}$ Amanda Moreno Miranda² Flavia Giron Camerini ${ }^{3}$ Vanessa Galdino de Paula ${ }^{4}$ Monica de Almeida Karam ${ }^{5}$ Roberto Carlos Lyra da Silva ${ }^{6}$}

Este é um estudo quantitativo, descritivo, com delineamento quase-experimental, com uso de simulador e, realizado em 2017 na cidade do Rio de Janeiro, e teve como objetivo avaliar a acurácia dos alarmes dos monitores multiparamétricos das principais arritmias nos pacientes em pós-operatório de cirurgia cardíaca. A primeira etapa constou da caracterização dos alarmes da unidade e avaliação da acurácia das variáveis de ritmo e frequência cardíaca dos monitores multiparamétricos provocadas pelo simulador de sinais vitais. Foram disparados 55 alarmes: frequência cardíaca, saturação, hipotensão e hipotermia somaram 84\% (n=46). Na acurácia diagnóstica, os monitores foram 100\% $(n=7)$ sensíveis para assistolia e taquicardia ventricular sem pulso, enquanto a fibrilação ventricular sem pulso e a fibrilação atrial de alta resposta soaram alarmes em apenas $43 \%(n=3)$. A tecnologia avaliada tem alta especificidade; no entanto, não é completamente sensível a ritmos fatais, tais como fibrilação ventricular sem pulso ou fibrilação atrial de alta e de baixa resposta, tornando os equipamentos pouco seguros na perspectiva dos alarmes.

Descritores: Alarmes clínicos; Confiabilidade dos dados; Cirurgia torácica; Arritmias cardíacas; Monitorização fisiológica.

This is a quantitative, descriptive study with quasi-experimental design, with the use of simulator, carried out in 2017 in the city of Rio de Janeiro, which aimed to evaluate the accuracy of the alarms of the multiparameter monitors related to the major arrhythmias in patients in the postoperative period of cardiac surgery. The first phase consisted of the characterization of the unit alarms and assessment of the accuracy of the rhythm and heart rate variables of multiparameter monitors caused by vital signs simulator. A total of 55 alarms were triggered: heart rate, saturation, hypotension, and hypothermia resulted in $84 \%(n=46)$. In the diagnostic accuracy, the monitors were $100 \%(n=7)$ sensitive to asystole, and pulseless ventricular tachycardia, while pulseless ventricular fibrillation and atrial fibrillation with rapid response caused the alarms to ring in only $43 \%(n=3)$. The technology evaluated has a high specificity; however, it is not quite sensitive to fatal rhythms, such as pulseless ventricular fibrillation or atrial fibrillation with rapid and slow response, making the equipments unsafe from the perspective of the alarms.

Descriptors: Clinical alarms; Data acccuracy; Thoracic surgery; Arrhythmias, Cardiac; Monitoring, Physiologic.

Este es un estudio cuantitativo, descriptivo, con delineamiento casi experimental, con uso de simulador y, realizado en 2017 en la ciudad de Río de Janeiro y, tuvo como objetivo evaluar la exactitud de las alarmas de los monitores multiparamétricos de las principales arritmias en los pacientes postoperatorios de cirugía cardíaca. La primera etapa consistió en la caracterización de las alarmas de la unidad y la evaluación de la exactitud de las variables de ritmo y frecuencia cardíaca de los monitores multiparamétricos provocadas por el simulador de signos vitales. Se dispararon 55 alarmas: frecuencia cardíaca, saturación, hipotensión e hipotermia sumaron un $84 \%(n=46)$. En la agudeza diagnóstica, los monitores fueron $100 \%(n=7)$ sensibles para asistolia y taquicardia ventricular sin pulso, mientras que la fibrilación ventricular sin pulso y la fibrilación auricular de alta respuesta, sonaron alarmas en sólo 43\% (n=3). La tecnología evaluada tiene alta especificidad, sin embargo, no es completamente sensible a ritmos fatales, tales como fibrilación ventricular sin pulso o fibrilación auricular de alta y baja respuesta, haciendo que los equipos sean inseguros desde la perspectiva de las alarmas.

Descriptores: Alarmas clínicas; Exactitud de los datos; Cirugía torácica; Arritmias cardíacas; Monitoreo fisiológico.

1. Enfermeira. Especialista em Terapia Intensiva. Especialista em Enfermagem do Trabalho. Mestre em Enfermagem. Doutoranda em Enfermagem e Biociência pela Universidade Federal do Rio de Janeiro (UNIRIO). Professora Assistente da Faculdade de Enfermagem da Universidade do Estado do Rio de Janeiro (UERJ), Rio de Janeiro, RJ, Brasil. ORCID: 0000-0001-5008-1345 E-mail: dezza.franco@gmail.com

2. Enfermeira. Especialista em Enfermagem Cardiovascular. Especialista em Enfermagem do Trabalho. Enfermeira da Unidade de Terapia Intensiva da Rede D'Or, Rio de Janeiro, RJ, Brasil. ORCID: 0000-0001-5810-3473 E-mail: amanda_enfermagem2010@hotmail.com

3. Enfermeira. Licenciatura em Enfermagem. Mestre e Doutora em Enfermagem. Professora Adjunta da Faculdade de Enfermagem da UERJ, Rio de Janeiro, RJ, Brasil. ORCID: 0000-0002-4230-953X E-mail: fcamerini@gmail.com

4. Enfermeira. Especialista em Docência do Ensino Superior. Especialista em Paciente Crítico Cardiológico. Especialista em Enfermagem MédicoCirúrgica. Mestre em Enfermagem. Doutora em Enfermagem e Biociências. Professora Assistente da Residência em Enfermagem em Terapia Intensiva e da Especialização em Enfermagem Intensivista da UERJ, Rio de Janeiro, RJ, Brasil. ORCID: 0000-0002-7147-5981 E-mail: vanegalpa@gmail.com

5. Enfermeira. Especialista em Enfermagem Cardiovascular. Especialista em Enfermagem em Clínica Médica. Mestre em Enfermagem. Professor Adjunto da Faculdade de Enfermagem da Universidade do Grande Rio, Rio de Janeiro, RJ, Brasil. ORCID: 0000-0003-1165-052X E-mail: monica.karam@unigranrio.br

6. Enfermeiro. MBA em Economia e Avaliação de Tecnologias em Saúde. Mestre e Doutor em Enfermagem. Professor Associado III do Programa de Pós Graduação em Enfermagem e Biociências da UNIRIO, Rio de Janeiro, RJ, Brasil. ORCID: 0000-0001-9416-9525 E-mail: proflyra@gmail.com 


\section{INTRODUÇÃO}

$\mathbf{0}$ presente estudo tem como tema a análise da efetividade dos alarmes de sinais vitais dos monitores multiparamétricos a partir do teste de acurácia diagnóstica realizada em cenário real de uma unidade cardiointensiva cirúrgica. Os alarmes representam mais uma barreira de proteção e, quando utilizados de modo adequado, podem contribuir para um cuidado seguro, na medida em que são fontes de informações primárias.

Apesar dos avanços tecnológicos na área da saúde, especificamente no que se refere aos sistemas de alarmes dos equipamentos de suporte avançado de vida, hoje se discute se eles estão mesmo oferecendo informação de qualidade em unidades de terapia intensiva (UTI), tendo em vista os problemas relacionados ao mau uso desse recurso ${ }^{1}$.

Esse questionamento parece ganhar mais sustentação nas recentes publicações ${ }^{2-5}$ que tratam da temática segurança do paciente e que fazem alusão ao uso abusivo de alarmes. Desde 2011, através do Emergency Care Research Institute (ECRI - Institute na Pensilvânia - EUA), uma instituição sem fins lucrativos que pesquisa as melhores práticas para procedimentos médicos, equipamentos, medicamentos e processos, publica anualmente uma lista que aponta os 10 maiores perigos em tecnologia em saúde, na qual os alarmes já estiveram no topo ${ }^{2}$.

$\mathrm{Na}$ última divulgação do documento com as dez principais tecnologias de saúde que apresentam perigo para 2018, o ECRI mantém os alarmes na lista, situando-os no 4o lugar e destaca a falha de alarmes resultante de dispositivos e sistemas de notificação secundária, configurados indevidamente ${ }^{2}$. 0 instituto defende que o alarme poderá não ser apenas um instrumento para garantia da segurança, mas a importância de se refletir sobre os riscos relativos ao soar dos alarmes quando não reconhecida a prioridade que merecem ${ }^{3}$.

Entende-se a importância e a inclusão do manejo dos alarmes, nas metas de segurança do paciente, com destaque também para educação dos profissionais de saúde, que necessitam conhecer melhor seus equipamentos médico assistenciais (EMA), os sistemas de alarmes, a confiabilidade destes alarmes e em especial, fazer a gestão dos alarmes para aumentar a margem de segurança ${ }^{4,5}$.

A cirurgia cardíaca é um exemplo de intervenção que requer um manejo adequado dos alarmes, uma vez que as arritmias fazem parte das principais complicações no pós operatório imediato. Trata-se de procedimento complexo que tem importantes repercussões orgânicas, alterando de diversas formas os mecanismos fisiológicos dos doentes, levando a um estado crítico pós-operatório que implica a necessidade de cuidados intensivos visando estabelecer uma boa recuperação dos pacientes ${ }^{6}$.

$\mathrm{Na}$ dependência do tipo de arritmia, das condições clínicas do paciente, da cardiopatia subjacente e da frequência cardíaca durante a arritmia, as alterações do ritmo cardíaco provocam repercussões variáveis sobre o débito cardíaco, consumo de oxigênio pelo miocárdio e fluxo sanguíneo coronariano. A queda do débito é mais intensa quando há disfunção ventricular associada, dissociação atrioventricular (como nos casos de taquicardia juncional não-paroxística ou taquicardia ventricular), ausência de contração atrial (como na fibrilação atrial) e presença de regurgitação mitral (como na taquicardia ventricular) ${ }^{7}$.

Diante do risco de possíveis complicações, o monitor, ao disparar um alarme consistente, poderá melhorar o senso de urgência e aumentar a confiabilidade da equipe para rápida resposta e pronta intervenção, minimizando os eventos adversos que a arritmia pode causar para este tipo de paciente. Ainda assim, o alarme pode ser disparado quando um dispositivo não está funcionando adequadamente e, os problemas nos dispositivos ou sistema incluem as conexões soltas ou os eletrodos não aderidos a pele, por exemplo. Mesmo que nada esteja errado com o paciente, estas condições devem ser corrigidas imediatamente ${ }^{8}$.

Contudo, quando um grande número de alarmes sobrecarrega a equipe, surge um problema denominado fadiga de alarmes. 0 fenômeno fadiga de alarme pode ser entendido como o retardo no tempo de resposta dos profissionais, podendo os alarmes serem desabilitados, silenciados ou ignorados, a equipe se torna insensível aos alarmes, e diminui seu 
estado de alerta ${ }^{9,10}$. Pode ser caracterizada pelo retardo no tempo ou pela falta de resposta da equipe aos alarmes, devido a um número excessivo de alarmes, resultando em sobrecarga sensorial e dessensibilização, com enorme repercussão e impacto negativo na segurança do paciente ${ }^{10}$.

Tendo em vista a dimensão desta problemática, surge a seguinte questão de pesquisa: 0 monitor multiparamétrico é sensível e específico o suficiente para identificar as principais arritmias, tendo em vista que estas são as principais complicações do pós-operatório de cirurgia cardíaca? Portanto, este estudo teve como objetivo avaliar a acurácia dos alarmes dos monitores multiparamétricos das principais arritmias nos pacientes em pós-operatório de cirurgia cardíaca.

\section{MÉTODO}

Trata-se de um estudo de abordagem quantitativa, descritiva, com delineamento quaseexperimental, uma vez que o estudo se propôs analisar o domínio técnico do equipamento, com direcionamento na perspectiva da segurança do paciente. Não houve experimento diretamente com pacientes, pois a identificação das arritmias foi feita através de um simulador.

O cenário do estudo foi uma Unidade Cardiointensiva Cirúrgica, que recebe pacientes adultos, em pós-operatório de cirurgia cardíaca de um hospital universitário no município do Rio de Janeiro. A unidade possui 13 leitos, dos quais 7 são utilizados exclusivamente para pacientes em pós-operatório de cirurgia cardíaca.

A coleta aconteceu em duas etapas distintas. Na primeira etapa foi feita a caracterização dos alarmes da unidade, sendo investidas 60 horas de observação e registro em instrumento próprio de coleta de dados, em forma de tabela. A escolha do tempo de coleta possui como referência os últimos estudos realizados de caracterização de alarmes de unidades de terapia intensiva ${ }^{11,12}$. Nesta etapa, foram ativados todos os alarmes dos monitores multiparamétricos e registrados os alarmes que mais soaram, bem como a variável fisiológica responsável pelo disparo.

Na segunda etapa foi realizada a avaliação da acurácia das variáveis ritmo e frequência cardíaca (FC), através de um simulador programado pelo pesquisador com as arritmias cardíacas mais frequentes para a clientela proposta (taquicardia ventricular, fibrilação ventricular sem pulso, fibrilação atrial de baixa resposta, fibrilação atrial de alta resposta). Nesta etapa, o pesquisador registrou o soar positivo ou o não soar do alarme à indução das arritmias e do ritmo sinusal para avaliar possíveis disparos indevidos. Esta informação alimentava os registros de sensibilidade e especificidade.

O simulador de sinais vitais utilizado é denominado HS-30, da marca RDMEDIQ ${ }^{\circledR}$. O HS30 é apresentado em cinco versões distintas, permitindo a simulação de sinais de eletrocardiograma (ECG), de oximetria, de respiração e de temperatura. Trata-se de um simulador de pacientes multifuncional combinado com simulador de ECG com 10 terminais (marcapasso cardíaco, de arritmias, de respiração, de temperaturas e de oximetria) ${ }^{13}$.

Para análise dos dados, optou-se pela aplicação da tabela de contingência denominada: 2x2 (dois por dois), utilizada nos testes diagnósticos. 0 diagnóstico correto e precoce, sobretudo das enfermidades graves, interfere de forma decisiva na história natural da doença, determinando condutas igualmente adequadas e consequentemente, maiores chances de desfechos favoráveis com menores custos financeiros e sociais ${ }^{14}$.

A validade de exame do teste diagnóstico (ETD) é composta por duas importantes propriedades: a sensibilidade (S) e a especificidade (E). Para analisar a sensibilidade (S) foi aplicada a seguinte fórmula matemática: $S=V P$ (Verdadeiro positivo) / Total de monitores e para analisar a Especificidade (E) aplicamos: E= VN (verdadeiro negativo) / Total de monitores. 


\section{RESULTADOS}

Os dados de caracterização dos alarmes disparados pelos monitores multiparamétricos podem ser visualizados na Tabela 1 . As alterações na frequência cardíaca (taquicardia e bradicardia), saturação, hipotensão e hipotermia somaram-se aproximadamente $84 \%(n=46)$. Também é possível notar que, dos alarmes disparados sem relevância clínica, foram encontrados: cabo de saturação solto, eletrodo solto, monitor ligado sem paciente, ausência de alterações fisiológicas e cabo de temperatura mal posicionado, totalizando em 15\% (n=8).

Tabela 1. Caracterização dos alarmes dos monitores multiparamétricos em simulador. Rio de Janeiro-RJ, 2017.

\begin{tabular}{lrr}
\hline \multicolumn{1}{c}{ Variáveis fisiológicas } & (n) & \% \\
\hline Taquicardia & 16 & 29 \\
Bradicardia & 15 & 27 \\
Saturação baixa & 9 & 16 \\
Hipotermia & 4 & 7 \\
Cabo de saturação solto & 3 & 6 \\
Hipotensão & 2 & 4 \\
Sem alteração fisiológica & 2 & 4 \\
Monitor ligado sem paciente & 1 & 2 \\
Hipertensão & 1 & 2 \\
Eletrodo solto & 1 & 2 \\
Cabo de temperatura solto & 1 & 2 \\
Total & $\mathbf{5 5}$ & $\mathbf{1 0 0}$ \\
\hline
\end{tabular}

No presente estudo, identificou-se que dos alarmes registrados, $49 \%(n=27)$ tiveram algum tipo de interferência por parte dos profissionais. Enquanto que em $51 \%(n=28)$ dos alarmes disparados não houve intervenção ou despertou qualquer estado de vigilância por nenhuma categoria profissional, pois o alarme silenciou sozinho. A categoria profissional que mais avaliou e interferiu durante o soar dos alarmes foi a equipe de enfermagem, composta por enfermeiros, residentes de enfermagem e técnicos de enfermagem, somando um total de 85\% $(n=23)$ das intervenções realizadas.

A análise da acurácia diagnóstica dos monitores multiparamétricos pode ser observada na Tabela 2.

Constatou-se que as arritmias, como assistolia e taquicardia ventricular sem pulso, foram $100 \%(n=7)$ sensíveis e $100 \%(n=7)$ específicas. Isto é, caso o paciente apresentasse assistolia ou taquicardia ventricular sem pulso, os monitores da unidade seriam capazes de gerar alarmes verdadeiros, ou seja, altamente sensíveis, nos assegurando também que na ausência destas arritmias um falso alarme não será gerado, caracterizando que o monitor também possui especificidade.

No que diz respeito a ritmos letais, os alarmes de Fibrilação Ventricular sem Pulso apresentaram 43\% (n=3) de sensibilidade e 100\% $(n=7)$ de especificidade. Ao simular uma FA de alta resposta, também ficou evidenciado sensibilidade de $43 \%(n=3)$ e especificidade de $100 \%(n=7)$. Enquanto que, se o paciente apresentar FA de baixa resposta, na referida unidade, o alarme do monitor não será capaz de disparar ( $0 \%$ de sensibilidade), diminuindo a possibilidade de identificação e possível intervenção da equipe de saúde. Embora se tenha $100 \%$ de especificidade neste teste, há de se considerar a gravidade de uma arritmia como quando esta não disparar o sistema de salvaguarda ao profissional de saúde. 
Tabela 2. Acurácia diagnóstica dos monitores multiparamétricos em simulador. Rio de JaneiroRJ, 2017.

\begin{tabular}{|c|c|c|c|c|c|c|}
\hline & $\begin{array}{c}\text { Acurácia } \\
\text { diagnóstica }\end{array}$ & Assistolia & $\begin{array}{c}\text { TV sem } \\
\text { pulso }\end{array}$ & $\begin{array}{c}\text { FV sem } \\
\text { pulso }\end{array}$ & $\begin{array}{c}\text { FA de alta } \\
\text { resposta }\end{array}$ & $\begin{array}{c}\text { FA de baixa } \\
\text { resposta }\end{array}$ \\
\hline \multirow{2}{*}{$\begin{array}{l}\text { Com } \\
\text { Arritmia }\end{array}$} & VP & 7 & 7 & 3 & 3 & 0 \\
\hline & FN & 0 & 0 & 4 & 4 & 7 \\
\hline \multirow{2}{*}{$\begin{array}{l}\text { Ritmo } \\
\text { Sinusal }\end{array}$} & VN & 7 & 7 & 7 & 7 & 7 \\
\hline & FP & 0 & 0 & 0 & 0 & 0 \\
\hline \multirow{2}{*}{ Total (\%) } & Sensibilidade & $100 \%$ & $100 \%$ & $43 \%$ & $43 \%$ & $0 \%$ \\
\hline & Especificidade & $100 \%$ & $100 \%$ & $100 \%$ & $100 \%$ & $100 \%$ \\
\hline
\end{tabular}

Legenda: VP: verdadeiro positivo (arritmia induzida e monitor alarmou); FN: falso negativo (arritmia induzida e monitor não alarmou); FP: falso positivo (ritmo sinusal e monitor alarmou); VN: verdadeiro negativo (ritmo sinusal e monitor não alarmou); Fórmula matemática de análise, considerando total de 7 monitores: Sensibilidade = VP/Total de monitores; Especificidade= VN/Total de monitores.

\section{DISCUSSÃO}

É importante descrever que os alarmes da unidade não são rotineiramente parametrizados, nem tão pouco são levadas em consideração as peculiaridades do paciente. Dessa forma, foram habilitados todos os alarmes antes da realização da coleta, pois algumas variáveis monitoradas estavam com os alarmes desabilitados.

Havia 7 monitores multiparamétricos disponíveis na unidade destinados aos pacientes em pós-operatório de cirurgia cardíaca. A partir da observação atenta do soar de alarmes, inferiu-se que as alterações na frequência cardíaca (taquicardia e bradicardia), saturação, hipotensão e hipotermia ocorreram com maior frequência. Esses achados são relevantes para avaliação e prevenção das principais complicações na cirurgia cardíaca que incluem arritmias e sangramentos, as quais afetam diretamente o débito cardíaco, levando a alterações hemodinâmicas supracitadas 15 .

Há de se considerar que a equipe somente poderia avaliar se um alarme é relevante ou não, atendendo e avaliando o paciente e a causa do disparo ${ }^{11}$ Sabe-se que os alarmes clínicos alertam quando a condição de um paciente está se agravando e/ou quando um dispositivo não está funcionando como deveria e, problemas de dispositivos ou sistema incluem conexões soltas. Portanto, mesmo que nada esteja errado com o paciente, estas condições devem ser corrigidas imediatamente ${ }^{8}$

Entretanto, estudos realizados_apresentaram evidências de que o elevado número de alarmes clinicamente irrelevantes ou falsos alarmes levam os profissionais a um estado de alerta reduzido, o que pode acarretar no retardo do tempo ou em falta de resposta aos alarmes relevantes ou verdadeiros que causam o fenômeno fadiga de alarmes, comprometendo desse modo a segurança do paciente na terapia intensiva ${ }^{1,2}$.

Um estudo mostrou que os prestadores de cuidados experientes não conseguiram identificar sequer a metade dos alarmes comuns disparados em CTI, quando reproduzidos ${ }^{9}$. A falta de treinamento tem como consequência o mau uso da tecnologia pela equipe e pode justificar a elevada incidência de alarmes falsos, estando o profissional despreparado para manusear os equipamentos médico assistenciais, gerando dificuldades na configuração das diversas funções desses dispositivos.

No que diz respeito aos alarmes que soaram e silenciaram sozinhos, os falsos alarmes distraem a atenção da equipe desnecessariamente e, portanto, são um incômodo. Na maioria dos casos estes alarmes de curta duração se autocorrigem. Exemplo desses alarmes é a saturação de oxigênio e a frequência cardíaca. Ambos os casos ocorrem com frequência, com o 
sinal de alarme vital voltando ao normal dentro de um intervalo de alguns segundos ${ }^{16}$. Caso parecido acontece quando um paciente intubado, que ao ser aspirado, pode desencadear um alarme de monitorização cardíaca e de ventilação mecânica que não necessitam de mudanças ou modificações nas programações, mas a ocorrência do alarme estimula o ambiente podendo acionar o profissional, para um "falso alarme", concorrendo quando um verdadeiro alarme for disparado.

Para atender a cientificidade do método de teste de acurácia diagnósticas, os achados foram descritos no tipo de tabela $2 \times 2$ de contingenciamento, porém para melhor entendimento optou-se por apresentar todos os resultados encontrados nos sete monitores multiparamétricos, como apresentado na Tabela 2.

Os estudos de acurácia diagnóstica tem como proposta avaliar a capacidade da tecnologia de realizar um dado diagnóstico. Assim, um teste de referência (padrão ouro) é empregado, e os resultados de acurácia (sensibilidade e especificidade) são apresentados diretamente ou são resultados que permitem o cálculo dessas medidas. Dessa forma, sensibilidade é a capacidade que o teste diagnóstico apresenta de detectar os indivíduos verdadeiramente positivos, ou seja, de diagnosticar corretamente os doentes. Já especificidade é a capacidade que o teste diagnóstico tem de detectar os verdadeiros negativos, isto é, de diagnosticar corretamente os indivíduos sadios ${ }^{17}$.

Foram induzidas, através do simulador HS-30, as cinco diferentes arritmias mais presentes no pós-operatório de cirurgia cardíaca. Pode-se observar que, caso o paciente apresentasse assistolia ou taquicardia ventricular sem pulso, os monitores da unidade seriam capazes de gerar alarmes verdadeiros, ou seja altamente sensíveis, assegurando também que na ausência destas arritmias, um falso alarme não seria gerado, caracterizando também o monitor como possuindo especificidade.

A taquicardia ventricular costuma aparecer entre as primeiras 48 horas até 7 dias após a cirurgia cardíaca e, apesar de pouco frequente, é potencialmente letal. Há relatos de mortalidade em até $44 \%$ dos pacientes acometidos ${ }^{7}$. As causas relatadas em estudo retrospectivo apontou hipoxia, distúrbios eletrolíticos (hipomagnesemia, hipocalemia) e do equilíbrio ácido-básico (acidose metabólica), infarto agudo do miocárdio, oclusão de enxertos coronarianos, isquemia, medicamentos (digital, fármacos simpaticomiméticos utilizados para suporte hemodinâmico, antiarrítmicos utilizados para o tratamento de outras arritmias, como a fibrilação atrial) e condições clínicas que evoluem com baixo débito cardíaco ${ }^{7}$.

Sob o ponto de vista de ser um dos ritmos mais letais e graves da parada cardiorrespiratória (PCR), a fibrilação ventricular sem pulso configura-se uma situação emergencial e extremamente preocupante quando o profissional de saúde não for acionado. Na PCR, o tempo variável é muito importante, estimando-se que, a cada minuto que o indivíduo permaneça em PCR, $10 \%$ de probabilidade de sobrevida sejam perdidos ${ }^{18}$.

Embora se tenha 100\% de especificidade neste teste, há de se considerar a gravidade de uma enfermidade quando esta não disparar o sistema de salvaguarda ao profissional de saúde.

A principal causa de PCR, no adulto, é fibrilação ventricular (FV). Esse distúrbio do ritmo cardíaco é ocasionado por mecanismo de reentrada, ocasionando contrações desordenadas e ineficaz das células cardíacas. É o distúrbio do ritmo cardíaco mais comum nos primeiros dois minutos de PCR, no adulto. Evolui, rapidamente, para assistolia, caso não sejam estabelecidas medidas de suporte básico de vida ${ }^{17}$.

Além disso, a principal causa de FV, nos casos de pós-operatório de cirurgia cardíaca, são as síndromes isquêmicas miocárdicas instáveis. Os pacientes mais propensos a taquiarritmias malignas têm história prévia de disfunção ventricular, taquicardia ventricular ou infarto do miocárdio ${ }^{17}$.

O diagnóstico correto e precoce, sobretudo das enfermidades graves, interfere de forma decisiva na história natural da doença, determinando condutas igualmente adequadas e 
consequentemente, maiores chances de desfechos favoráveis com menores custos financeiros e sociais ${ }^{14 .}$

$\mathrm{Na}$ análise da acurácia, as arritmias mais presentes em no cenário apresentado e elencadas neste estudo, foram os dados encontrados no estímulo de FA de baixa resposta pelo simulador.

Caso o paciente apresente FA de baixa resposta na referida unidade, o alarme do monitor não será capaz de ser disparado, diminuindo a possibilidade de identificação e possível intervenção da equipe de saúde. É uma taquiarritmia supraventricular caracterizada por ativação atrial desordenada, com consequente deterioração da função atrial. Sua incidência é estimada entre 20 e $40 \%$ e sua ocorrência é mais frequente entre o $2^{\circ}$ e o 5ํㅜ dias após a cirurgia cardíaca ${ }^{17}$.

O tempo de permanência na UTI dos pacientes que desenvolvem FA no pós operatório, aumenta em média dois a quatro dias em relação aos que mantém o ritmo sinusal. Essa complicação também é a principal causa de readmissão hospitalar após a alta de cirurgia cardíaca. Acidente vascular cerebral (AVC), hipotensão arterial, edema agudo de pulmão, maior tempo de permanência na UTI e custos adicionais elevados estão diretamente associados à FA no pós- operatório, assim como o aumento da morbimortalidade 17.

Cabe aqui descrever que, embora tenha sido utilizado os termos FA de baixa e alta resposta, referindo-se a resposta ventricular que produz traçados finos e grosseiros, respectivamente, observados no monitor, de acordo com a última Diretriz Brasileira de Fibrilação Atrial de 2016, a classificação mais utilizada na prática clínica refere-se a forma de apresentação clínica da $\mathrm{FA}^{18}$. De acordo com essa diretriz, define-se como FA paroxística aquela que é revertida espontaneamente ou com intervenção médica em até 7 dias de seu início. A FA persistente é quando os episódios duram mais que 7 dias. A terminologia de FA persistente de longa duração é utilizada para designar os casos com duração superior a 1 ano. Outra denominação é de FA permanente nos casos em que as tentativas de reversão ao ritmo sinusal não serão mais instituídas. E por fim, FA não valvar reconhecida na ausência de estenose mitral reumática, válvula mecânica ou biológica ou plastia mitral prévia ${ }^{18}$.

Diante dos achados, as informações adquiridas fazem refletir sobre a importância da adequada gestão das tecnologias duras na saúde visando otimizar a segurança do paciente, evitando problemas como falta de manutenção, manutenção inadequada, compra de peças incompatíveis, falta de planejamento de compra, entre outras. 0 gerenciamento das mesmas em estabelecimentos de saúde se tornou uma exigência regulamentada pela Agência Nacional de Vigilância Sanitária (ANVISA) por meio da RDC Nº2 de 25 de janeiro de 2010 e da RDC N ${ }^{\circ}$ 20 de 26 de março de $2012^{19,20}$. Além disso, vale notar que, embora um dos pré-requisitos para este gerenciamento seja formação superior, a resolução não especifica a categoria profissional para exercer tal função no seu artigo de número 8 , o que pode ser de grande proveito para os usuários se a enfermagem fizer parte de grupos especializados neste segmento tecnológico.

As Avaliações de Tecnologias em Saúde (ATS) no mundo todo, predominantemente tem sido focadas em medicamentos, dispositivos médicos terapêuticos e procedimentos, sobretudo, os cirúrgicos. Assim sendo, compreender os instrumentos de ATS nesse contexto é fundamental para subsidiar o raciocínio clínico, direcionar os profissionais às boas práticas em saúde que resultem em benefício e segurança aos pacientes, além de racionalizar os custos para os sistemas de saúde e auxiliar os gestores da saúde na tomada de decisão com base em informações compreensíveis e confiáveis ${ }^{14}$.

Neste sentido, compreende-se que o setor da Engenharia Clínica tem fundamental importância na unidade hospitalar, pois evita prejuízos como a elevada quantidade de manutenções corretivas ou aproveitamento incompleto ou equivocado dos equipamentos médico assistenciais que possam refletir em danos ao paciente, bem como aumento dos custos assistenciais. Além disso, pode contribuir para a produção de outras pesquisas que colaborem para a ATS, cuja temática tem sido bastante incentivada tanto por setores públicos quanto 
privados, emergindo como política pública em saúde desde 2010. Vale ressaltar que a Engenharia Clínica da unidade em estudo foi comunicada sobre as ocorrências encontradas nos monitores após os achados deste estudo, afim de gerar ordem de serviço e possível avaliação do monitor.

\section{CONCLUSÃo}

Através deste estudo no cenário abordado, conclui-se que a frequência cardíaca foi a maior causa de alarmes durante o período de observação. Contudo, a tecnologia avaliada tem alta especificidade. No entanto, não é completamente sensível a ritmos fatais tais como FV sem pulso, FA de alta resposta e FA de baixa resposta, pois não atende aos critérios de acurácia utilizados neste trabalho para o reconhecimento das arritmias simuladas, o que a torna insegura como sistema de salvaguarda durante o pós-operatório e, por vezes, no transporte e transoperatório.

A análise da frequência e ritmo cardíacos são importantes aliados para avaliar as condições clínicas de pacientes críticos, uma vez que suas variações podem provocar graves repercussões hemodinâmicas. Entretanto, os alarmes de tais variáveis, como sistemas de salvaguarda, precisam ser eficazes. Para isso, o alarme deve ser clinicamente relevante por um problema que, de fato, alerte para as necessidades do paciente, e a equipe deve agir de forma resolutiva quanto a origem e o significado do alarme, corrigindo o problema antes que um evento adverso ocorra.

Neste contexto, a equipe de enfermagem, tem maior participação para identificar importantes alterações hemodinâmicas, além de situações sem relevância clínica e, inclusive falsos alarmes, provavelmente devido ao maior tempo próximo ao leito e às constantes avaliações. Assim, a segurança do paciente depende de uma equipe devidamente dimensionada, treinada e preparada para otimizar intervenções precocemente enquanto o evento pode ser evitado, como também nas situações de cunho emergencial.

Percebe-se, portanto, que apesar de sua inquestionável importância na história natural de um grande número de doenças e do impacto econômico associado ao seu uso, os testes diagnósticos, considerando-se suas qualidades e consequentemente a acurácia, tem sido pouco utilizados, especialmente em tecnologias.

Embora seja importante capacitar_a equipe sobre a gestão de alarmes e a parametrização, não há aplicabilidade se o alarme não tocar. Além disso, há nítida escassez de estudos que avaliam os testes diagnósticos tanto do ponto de vista clínico e de segurança para o paciente, quanto do econômico. Apesar de inúmeros estudos sobre o fenômeno fadiga de alarmes, pouco se conhece sobre a confiabilidade do parque tecnológico nas unidades de terapia intensiva, contribuindo para avanço na área de ensino e pesquisa na enfermagem.

A partir dos resultados encontrados, este estudo permitiu ainda a reflexão que a estratégia de intervenção mais apropriada e segura parece ser o envolvimento da engenharia clínica na prevenção e, em especial, manutenção corretiva dos monitores que demonstraram não possuir acurácia, oferecendo insegurança para os pacientes. Além disso, o envolvimento dos gestores em estudos de ATS pode contribuir significativamente para a possível incorporação de tecnologias mais seguras do ponto de vista da cirurgia cardiovascular.

\section{REFERÊNCIAS}

1. Silva RCL, Kaczmarkiewicz CC, Cunha JJSA, Meira IC, Figueiredo NMA, Porto IS. O significado da tecnologia no pós-operatório imediato de cirurgia cardíaca. Rev SOCERJ [Internet]. 2010 $\begin{array}{lllllll}\text { [citado em } 02 \text { jan 2017]; } 22 & \text { (4):210-8. Disponível em }\end{array}$ http://sociedades.cardiol.br/socerj/revista/2009_04/a2009_v22_n04_02rcarlos.pdf

2. Emergency Care Research Institute. Health Device. Top 10 health technology hazards for 2018 [Internet]. 2017 [citado em 10 nov 2017]. Disponível em: https://www.ecri.org/Pages/default.aspx 
3. Paine CW, Goel VV, Ely E, Stave CD, Stemler S, Zander M, et al. Systematic review of physiologic monitor alarm characteristics and pragmatic interventions to reduce alarm frequency. J Hosp Med [Internet]. 2016 [citado em 4 abril 2017]; 11(2):136-44. DOI: 10.1002/jhm.2520

4. Ribeiro GSR, Silva RCF, Márcia A, Silva GR. Violações no uso de equipamentos por enfermeiros na terapia intensiva. Texto \& Contexto Enferm. [Internet]. 2017 [citado em 2 dez 2017]; 26(2):e6050015. Disponível em: http://www.scielo.br/pdf/tce/v26n2/pt_0104-0707tce-26-02-e6050015.pdf. DOI: http://dx.doi.org/10.1590/0104-07072017006050015

5. The Joint Commission. Alarm safety webinar [Internet]. 2013 [citado em 4 abril 2017]. Disponível

https://www.jointcommission.org/assets/1/6/Alarm_Safety_webinar05113_transcript.pdf

6. Soares GMT, Ferreira DCS, Gonçalves MPC, Alves TGS, David FL, Henriques KMC, et al. Prevalência das principais complicações pós-operatórias em cirurgias cardíacas. Rev Bras Cardiol. [Internet]. 2011 [citado em 2 dez 2017]; 24(3):139-46. Disponível em: http://sociedades.cardiol.br/socerj/revista/2011_03/a_2011_v24_n03_01prevalencia.pdf

7. Moreira DAR. Arritmias no pós-operatório de cirurgia cardíaca. Rev Soc Cardiol Estado de São Paulo [Internet]. 2001 [citado em 11 jan 2017]; 11(5). Disponível em http://geicpe.tripod.com/cirur_urct_arritmias.htm

8. Sendelbach S, Stacy Jepsen S. American Association of Critical Care Nurses (AACN). Alarm management: scope and impact of the problem [internet]. 2013 [citado em 02 jan 2017]. Disponível em: http://www.aacn.org/wd/practice/docs/practicealerts/alarmmanagementpractice-alert.pdf

9. Mondor TA, Finley GA. The perceived urgency of auditory warning alarms used in the hospital operating room is inappropriate. Canadian J Anesth. [Internet]. 2003 [citado em 11 dez 2017]; 50(3):221-8. Disponível https://link.springer.com/content/pdf/10.1007\%2FBF03017788.pdf

10. Cvach M. Monitor alarm fatigue: an integrative review. Biomed Instrum Technol. [Internet]. 2012 [citado em 12 dez 2017]; 46(4):268-77. Disponível em: https://www.aamibit.org/doi/pdf/10.2345/0899-8205-46.4.268

11. Bridi AC, Silva RCL, Farias CCP, Franco AS, Santos VLQ. Tempo estímulo-resposta da equipe de saúde aos alarmes de monitorização na Terapia Intensiva: implicações para segurança do paciente grave. Rev Bras Ter Intensiva [Internet]. 2014 [citado em 09 dez 2017]; 26(1):28-35. Disponível em: http://www.scielo.br/pdf/rbti/v26n1/0103-507X-rbti-26-01-0028.pdf. DOI: http://dx.doi.org/10.5935/0103-507X.20140005

12. Franco AS, Bridi AC, Silva RCL, Oliveira RSL. Tempo estímulo-resposta aos alarmes do balão intraórtico: práticas para cuidado seguro. Rev Bras Enferm. [Internet]. 2017 [citado em 06 jan 2018]; 70(6):1206-11. Disponível em: http://www.scielo.br/pdf/reben/v70n6/pt_00347167-reben-70-06-1206.pdf DOI: http://dx.doi.org/10.1590/0034-7167-2016-0432.

13. Weill G, Motamed C, Eghiaian A, Monnet X, Suria S. Comparison of Proaqt/Pulsioflex® and oesophageal Doppler for intraoperative haemodynamic monitoring during intermediate-risk abdominal surgery. Anaesth Crit Care Pain Med. [Internet]. 2019 [citado em 11 mai 2019]; 38(2):153-9. DOI: https://doi.org/10.1016/j.accpm.2018.03.011

14. Nunes AA; Martinez EZ; Ana LW; Pazin-Filho A; Coelho EB; Mello LM. Testes diagnósticos no contexto da avaliação de tecnologias em saúde: abordagens, métodos e interpretação. Medicina (Ribeirão Preto, Online) [Internet]. 2015 [citado em 11 maio 2019]; 48(1):8-18. DOI: http://dx.doi.org/10.11606/issn.2176-7262.v48i1p8-18

15. Sowan AK, Tarriela AF, Gomez TM, Reed CC, Rapp KM. Nurses' perceptions and practices toward clinical alarms in a transplant cardiac intensive care unit: exploring key issues leading to alarm fatigue. JMIR Hum Factors [Internet]. 2015 [citado em 12 abr 2019]; 2(1):e3.2015. Disponível em: https://humanfactors.jmir.org/2015/1/e3/pdf. DOI: http://doi.org/10.2196/humanfactors.4196 
16. Welch J. Alarm fatigue hazards: the sirens are calling. Patient Saf Qual Healthcare [Internet]. 2012 [cited 2012 jun 16]; 9(3):26-9,32-3. Disponível em: http://psnet.ahrq.gov/resource.aspx?resourceID=24671

17. Sobral MLP, Barbieri LR, Gerônimo GM S, Trompieri DF, Souza TA, Rocca JMG, et al. 0 impacto da fibrilação atrial no pós-operatório de revascularização do miocárdio. Relampa, Rev Lat-Am Marcapasso Arritm. [Internet]. 2013 [citado em 13 jun 2019]; 26(3):137-43. Disponível em: http://www.relampa.org.br/detalhe_artigo.asp?id=901

18. Magalhães LP, Figueiredo MJO, Cintra FD, Saad EB, Kuniyoshi RR, Teixeira RA, et al. II Diretrizes Brasileiras de Fibrilação Atrial. Arq Bras Cardiol. [Internet]. 2016 [citado em 13 jun 2019]; 106(4 Supl 2):1-22. Disponível em:

http://publicacoes.cardiol.br/2014/diretrizes/2016/02_II\%20DIRETRIZ_FIBRILACAO_ATRI AL.pdf

19. Ministério da Saúde (Brasil), Agencia Nacional de Vigilância Sanitária. Diretoria Colegiada. Resolução-RDC № 2, de 25 de janeiro de 2010. Dispõe sobre o gerenciamento de tecnologias em saúde em estabelecimentos de saúde [Internet]. D.O.U. Brasília, DF, 25 jan 2010 [citado em 13 jun 2019]; Seção 1(16): 79. Disponível em: https://www20.anvisa.gov.br/segurancadopaciente/index.php/legislacao/item/rdc-2-de-25de-janeiro-de-2010

20. Ministério da Saúde (Brasil). Agencia Nacional de Vigilância Sanitária. Resolução - RDC № 20, de 26 de março de 2012 [Internet]. 2012 [citado em 13 jun 2019]. Disponível em: http://bvsms.saude.gov.br/bvs/saudelegis/anvisa/2012/rdc0020_26_03_2012.html

\section{CONTRIBUIÇÕES}

Andrezza Serpa Franco e Amanda Moreno Miranda contribuíram na concepção do estudo, coleta e análise dos dados, redação e revisão. Flavia Giron Camerini participou da concepção do estudo e redação. Roberto Carlos Lyra da Silva, Vanessa Galdino de Paula e Monica de Almeida Karam contribuíram na revisão.

\section{Como citar este artigo (Vancouver)}

Franco AS, Miranda AM, Camerini FG, Paula VG, Karam MA, Silva RCL. (In) segurança dos monitores multiparamétricos na cirurgia cardíaca: um estudo de acurácia diagnóstica. REFACS [Internet]. 2020 [citado em inserir dia, mês e ano de acesso]; 8(1):57-66. Disponível em: inserir link de acesso. DOI: inserir link do DOI.

\section{Como citar este artigo (ABNT)}

FRANCO, A. S.; MIRANDA, A. M.; CAMERINI, F. G.; PAULA, V. G.; KARAM, M. A.; SILVA, R. C. L. (In) segurança dos monitores multiparamétricos na cirurgia cardíaca: um estudo de acurácia diagnóstica. REFACS, Uberaba, v. 8, n. 1, p. 57-66, 2020. Disponível em: inserir link de acesso. Acesso em: inserir dia, mês e ano de acesso. DOI: inserir link do DOI.

\section{Como citar este artigo (APA)}

Franco, A.S., Miranda, A.M., Camerini, F.G., Paula, V.G., Karam, M.A. \& Silva, R.C.L. (2020). (In) segurança dos monitores multiparamétricos na cirurgia cardíaca: um estudo de acurácia diagnóstica. REFACS, 8(1), 57-66. Recuperado em: inserir dia, mês e ano de acesso de inserir link de acesso. DOI: inserir link do DOI. 